\title{
Gendering 'Soft' Policing: Multi-Agency Working, Female Cops, and the Fluidities of Police Culture/s
}

\author{
D J McCarthy, University of Surrey, UK \\ May 2012 accepted, in press Policing and Society
}

\begin{abstract}
This article examines the role of female police officers within the context of developing 'soft' policing initiatives designed to divert young people away from crime. Within the police culture literature, a masculine model of policing associated with coercive crime fighting tasks is often contrasted with a more cooperative, problem-solving and compassionate mode of police work. The latter model is viewed as serving to create a more legitimate structure for female police officers to work within, involving increasing trust and cooperation in communities and engaging with community crime prevention strategies. The aim of this article is to assess the role of female police officers within recent changes under the auspices of community policing reform in England and Wales, highlighting the role of female officers in enacting 'soft' policing initiatives in collaboration with social work and other community agencies. This raises some limitations of the conventional police culture literature by illustrating the ways these operations have carved a niche for female officers, in addition to altering the style of policing across certain sections of the organisation more generally.
\end{abstract}

Keywords: Soft policing, occupational culture, gender, multi-agency working

\section{Introduction}

'Soft' policing - an amalgam of activities which include supporting and mentoring young people 'at risk' of crime, and building community trust relations - has frequently been treated with animosity amongst police officers. This animosity has traditionally consisted of police officers judging 'soft' community-based policing tasks as departing from 'proper' images of police work associated with masculine ideals of crime fighting (Holdaway, 1983, Fielding, 1994, Herbert, 1997). In recent years successive community policing reforms in a number of Western nation states have sought to expand the remit of policing to encompass activities beyond problems of crime and disorder. In the U.K specifically, these include the importance of building trust relations between police and communities, increasing levels of social capital, and implementing a range of community crime prevention programmes to work with disadvantaged young people and families (Home Office, 2004, 2010) ${ }^{1}$. These developments have created several openings and opportunities for female officers to enact occupational identities which can gain legitimacy in the overall police organisation. However, at the same time it has been well documented that the occupational values of the police have continued to place most regard on crime fighting activities and on maintaining conservative moralities which have largely inhibited successful opportunities for reform (Chan, 1997 ${ }^{2}$, Herbert, 2005).

This paper examines the role of female police officers, as well as related auxiliary staff such as police community support officers (PCSOs) $)^{3}$ in the everyday practices of 'soft' policing, developing earlier work by authors such as Martin (1980), Heidensohn, (1992), Miller (1999) and Westmarland (2001) who have examined the role of female police officers in masculine police occupational cultures. The paper challenges conceptions of female officers as either subservient and marginalised by police cultures, or otherwise active 
proprietors of the masculine values of the police organisation as an enforced coping mechanism. It is argued that there are important gender distinctions in the ways certain 'soft' policing activities are both framed and enacted, particularly the impact of multi-agency working between the police and social welfare agencies. These organisational networks challenge typical policing structures by aligning the police in collaborative decision-making with other community agencies, and by having a greater number of female officers operating within these networks. Throughout this paper an examination of the police occupational culture literature takes place by way of connection with the context of the 'soft' policing examples analysed through ethnographic fieldwork data. This will aim to illustrate how the celebration of, and indeed resistance to, these policing activities actually results in more of a trade-off of occupational forms, rather than a hegemonic domination of one set of values over another. This suggests that amongst a mix of cultural elements at work, pragmatism is arguably the biggest factor in the adoption or rejection of 'soft' policing activities by streetlevel officers. In the case of one fieldwork locale in particular, this led to legitimacy amongst officers who were either previously critical of 'soft' policing styles, or who occupied roles disconnected from community policing. As well as these issues, the collaborative practices of the police engaged in 'partnership' working with other local agencies leads to questions about how far these working relations affect the police organisation, and how far this assimilates into the occupational values of the police in accordance with 'soft' rather than intrinsically 'hard' policing activities and functions.

In what follows, the roles of male and female police officers within 'soft' policing arrangements will be analysed by drawing on a two-year ethnographic study carried out in two locales outside London, England. It is argued that there are several limitations of the current literature on police occupational culture. Firstly, that despite previous issues raised by policing scholars (esp, Fielding, 1994, Reiner, 2000, Herbert, 2001, Paoline, 2003), police culture is neither monolithic nor homogenous; there are few recent accounts which demonstrate recognition of the contradictions, fluidities, and complexities of culture and its operations. This critique embraces much of the ethnographic style of symbolic interactionism in reconciling the portrayal of these accounts in a style which accords with a sociological 'messiness'. Secondly, as has recently been well documented by Loftus (2009), police culture literature continues to operate in rather orthodox ways despite a great deal of organisational change during the past two decades. Although there are indeed merits of such accounts in displaying the continuities of policing cultures, more 'alternative' policing activities such as those analysed during this paper can illuminate a more complex picture of cultural practice. Of especial importance are the ways through which resistance and compromise are embraced by officers in adopting pragmatic styles of policing which are seen to work on the ground, yet occur through a set of styles which must operate to subvert negative connotations such as those of 'pink and fluffy' or 'airy fairy' policing by traditional 'masculinised' standards of police culture ${ }^{4}$. It will be argued that female officers operate in quite mixed and contradictory ways within 'soft' policing practices - neither projecting a constant 'feminised', nor fully masculinised persona - with the outcome that this subject positioning preserves the legitimacy and acceptance of 'soft' policing measures within what still can be defined ultimately as a masculinised institution.

\section{Soft Policing, Gendered Labour and Culture}

Several authors have noted that 'soft' policing activities have traditionally been considered inferior forms of police work compared with more authoritarian functions which rest on physical prowess, taking control of potentially dangerous situations, and which largely stem from a perspective associated with crime fighting (Holdaway, 1983, Fielding, 1994, 
Westmarland, 2001). Authors including Herbert (2005) have further illustrated how aspects of 'soft' policing associated with engaging with communities in order to produce greater trust relations and networks of control, have been blighted by the occupational values of predominantly male officers who view increasing policies to promote citizen interaction as diminishing their powers by challenging their vested authority to determine ways to provide public safety.

Research has also analysed the formation of gender identities within police work. During her study of gender identity and policing, Susan Martin (1980) argued that female officers either over-emphasise idealised gendered identities in their occupational identity (passivity, being subordinate, weak leadership etc) or identities which sideline their gendered attributes to the occupational status of being a cop (aggressive, taking control, rational, competent, action-orientated). In a later article she revisited similar themes to shed light on the different ways male and female police officers perform their duties in accordance with the emotional dynamics of their encounters (Martin, 1999). Martin again highlights the dominance of male value systems in structuring the hierarchical allocation of labour, with social service activities firmly at the bottom of the pile even with the greater role of community policing:

Neither the rise of community policing nor the growing presence of women in policing has led to explicit discussion of the emotional component of the work. Male antipathy for the social services aspects of police work continues, and women either share the men's views or adapt to the fact that crime control rather than social service persists as the central occupational image. (Martin, 1999:121)

Additional US accounts such as those of Miller (1999) and Rabe-Hemp (2009) have similarly argued that the division of labour created within the police organisation tends to place social service activities at the margins, whilst at the same time acknowledging the possibilities provided by community policing and similar service-orientated policing activities in presenting an arena where women can be accepted. Miller (1999) found female officers were drawn to community policing by social work qualities such as building interpersonal links with citizens, compared with male officers who viewed these functions to be secondary to law enforcement activities. In addition, female officers were attracted to community policing roles for reasons beyond gaining promotion, such as the will to help communities. Ethnographic research from the U.K, in particular the work of Westmarland (2001), has drawn attention to the ways in which female officers are not always peripheral to the dominant culture of the police organisation, but are allowed to find niche specialisms in areas such as domestic violence and child protection, which can offer them promotional opportunities. The heroic, masculine pursuits of 'action orientation' and 'crime fighting', according to Westmarland, still function as key instruments of organisational integrity for male officers, to the detriment of broader social service activities which continue to be regarded as 'feminine tasks' and more suited to the assumed emotional capacities of female officers. Fielding and Fielding (1992) also found male officers held sceptical attitudes to the involvement of female officers in street policing, mostly reverberating around their lack of physical strength, which was viewed by male respondents to be a vital component of police work.

The occupational culture literature incorporates a plethora of explanations for the interactionist features of how policing as a social practice can be altered through particular contexts and in accordance with the gender and other characteristics of the officers involved. However, the focus on occupational culture can subordinate key material questions about the gendered division of labour within the police institution. This recognises that occupational values are channelled through forms of legal power and patriarchal norms serving as 
structural components which set limits and possibilities to the operations of culture (Chan, 1997, Herbert, 1998, Fielding, 2002). It has been well recognised through an abundance of literature charting the experiences of female police officers, that there are several structural barriers which set limits to career progression, especially to senior ranks (Brown, 1998), movement into certain types of police work, such as detective work (Holdaway and Parker, 1998), the role of sex discrimination legislation (Martin, 1980, Heidensohn, 1992, Brown and Heidensohn, 2000), and the political changes which have encouraged certain policing styles over others (Fielding, 2005).

Much of these structural inequalities within the police organisation can also be linked to institutions beyond the police (Walby, 1997), although one should also recall that in England and Wales it is only since the 1970s that female officers have had the opportunity to work alongside male officers in general policing roles; up to this point, a two tiered system of policing structured by gender was in operation (Heidensohn, 1992). Prior to the 1970s, police work for women was 'mainly confined to moral and sexual matters and inevitably making female officers complicit in the control of their own sex in ways which men's behaviour was not controlled' (Heidensohn, 1992: 52). In contemporary divisions of labour within the police organisation there is still strong evidence to suggest that female officers tend to occupy positions linked to social service operations, inter alia associated with activities orientated with community policing work. For female officers who tend to be marginalised from wider policing activities such as detective work or the drugs squad, this can create barriers for career progression into senior ranks (i.e. Association of Chief Police Officer level) through possession of a limited portfolio (Holdaway and Parker, 1998). Whilst structural dynamics do indeed create these divisions, this should not necessarily lead to the destined view that female police officers as subjected to a 'soft' policing 'ghetto' which ultimately confines them to subordinated roles within the police. Rather, as this paper will argue, female officers often readily employ subversive and creative methods which allow particular modes of police work to be adopted within more general policing roles - specifically beyond those confined to their historic position within the police division of labour.

\section{A Note on Fieldwork and Method}

The data informing this paper comes from a two-year ethnographic study in two community police departments, working in conjunction with other agencies including housing, mental health, social work and probation services. The author was engaged in observation of multiagency meetings involving a range of rank-and-file and senior-level officers, which involved ways of dealing with local problems of crime and incivilities through direction of multiagency responses. These consisted of the police taking on a role which involved ongoing collaborative problem-solving work with other community agencies, e.g. the setting-up of outreach support for young people, and diversionary programmes, as well as information sharing and surrogate forms of surveillance within these provisions.

The two field settings were located within a twenty mile radius of London, UK. One locale [Hobart] had a well established infrastructure of community policing which dated back to the 1970s. The other locale [Shore Acres] had a developing community policing philosophy which had been driven directly from the Home Office's National Reassurance Policing Programmes (Home Office, 2004), and is therefore somewhat less 'organic' than Hobart's history of community policing. Both areas had an extended policing team for each estate - usually covering an approximate 3-4 mile radius - consisting of not only police

officers, but also auxiliary officers such as special constables and more commonly, Police Community Support Officers (PCSOs). Both field sites were comparable in terms of socio- 
economic variables such as crime rates, levels of inequality, population, and proportion of minority ethnic groups which was average for the U.K.

The typical composition of the case conference meetings in each area was the meeting chair - a female police inspector in Hobart, and a male Local Authority Officer in Shore Acres, two police Sergeants - usually both female ${ }^{5}$, an average of six police and PCSO officers - 40/60\% male/female, drugs workers x 2 (female), mental health worker $x$ 1(female), housing officers x 3 (male/female mixed), youth offending team workers x 1-2 (female), social workers x 2 (m/f mixed), Education Welfare Officers x 1 (female), local authority staff (2 (m/f mixed), and Children's Services x 2 (mostly female). Some additional agencies would also attend meetings, although these were less consistent than those mentioned. Professionals were predominantly white European, aged between 25 and 45, and had been in service for a minimum of two years and a maximum of 25 years.

In conjunction with observation of multi-agency meetings, time was also spent shadowing and carrying out regular informal interviews with police officers. Over 1,000 pages of fieldnotes were compiled during the two years of research, consisting of 200 hours of observation of case conference meetings. A further 18 in-depth qualitative interviews were carried out at the end of the fieldwork as an additional method of triangulation in order to test the validity of themes established during the ethnographic component of the study (Flick, 1998). The two years spent in the field was also favourable for earning trust with the police officers who were generally willing to provide information and expressed interest in my research. These data forms were coded using the qualitative software package Nvivo using thematic analysis techniques advocated by Boyatzis (1998). This method of thematic analysis began by coding large sections of data (around one paragraph each) as an initial way of managing the data before more intensive, in-depth coding could be completed. Coding took place from the beginning of the data collection point, then after six months in the field where a sizeable amount of data had been gathered (approx 250 pages of fieldnotes), principle codes which had been identified as strong themes within the overall data were highlighted and tested during subsequent observations in order to find confirming or contingent features within each theme. Following Patton (2002) the broad creation of thematic codes stemmed from what he terms 'intensity sampling' whereby 'one seeks excellent or rich examples of interest, but not highly unusual cases' (Patton, 2002: 234). At the same time however, the development and reformulation of themes did allow some 'deviant' cases (Becker, 1998) to emerge which were exceptions to normal observations, yet conveyed important insights into the particulars of more general social patterns. This was important in theory 'testing' in order to consider instances which did not always follow typical conventions.

\section{Findings}

\section{The Philosophy of Early Intervention}

The relationship between organisational change and occupational values is often depicted as the key factor associated with the success or failure of reform efforts (Chan, 1997). In the context of this paper, organisational change took place in Hobart through the pragmatic vision of middle-level management staff that saw the police's role as ineffective in dealing with the many social problems affecting young people and their families. In the case of Hobart, the police officers driving these organisational changes happened to be all female at Sergeant level or above. The successful assimilation of what will be defined more broadly as "early intervention' policies, were supported by male senior officers (Superintendents, up to the Chief Constable) whose perspectives, although not necessarily driven by benevolent values, championed the potential cost savings and broader multi-agency links which could be fostered 
by the police. This occurred during the late 1990s with growing numbers of attendees, as well as decent funding from the central police and other local agencies. By the start of the fieldwork, the programme had been in operation for over 10 years. Vicky, one of the key officers involved in setting up the multi-agency case conference group gave her account of the reasons for its introduction:

It was supposed to be a helping process and preventive process and everything else. Everyone bought into that and obviously I think in the first few months we were able to prove that we weren't just setting things up so that we could get as much information as we could so that we could go out and bosh the doors in [laughs]. I think even there was some scepticism with the police about working with other partners. We had an example really early on in 2001, where the police had gone to the meeting with the ASBO [Anti-Social Behaviour Order] hat on. It was a juvenile, he was about 16. He had come from nowhere this lad. In the previous couple of months we knew he was responsible for breaking into vehicles - and massive amounts of them, and stealing cars. He was doing like ten a night. We had gone to the meeting and threw it on the table 'right we are going to ASBO him', doesn't matter what you lot say, this is what we are going to do. Because we had the partners around the table and the information was shared. 'Do you know his father has just got Huntingdon's disease', the father found out about six months ago. The father is at home deteriorating rapidly and about two months ago the son was told that it's highly hereditary and you have a $50 \%$ chance of developing it yourself. All of a sudden this lad in the prime of his life was told you have a 50\% chance of catching what your Dad's having. So this lad thought 'well if I am going to go out then I might as well go out with a bang'. Nobody had offered him any counselling, nobody had offered him the test which he could find out if he had the gene which could develop. All of a sudden everyone was able to see the benefits of partnership working and sharing information. We were able to offer him counselling and then the test, and within six months he stopped offending. [Interview with Vicky, Police Sgt - Hobart]

The formation of the multi-agency initiative occurred under the framework of the Neighbourhood Policing teams, encompassing police beat officers, child protection, domestic abuse, and officers specialising in other service roles. The management structure of the team consisted of the Community Safety Inspector at the command level. In Hobart, Kate and Vicky existed at mid-management/Sergeant level, with approximately 20 uniformed officers, and a team of administrative staff. Apart from the uniformed officers who had an even ratio of male and female officers, the majority of the team was female. In overall terms, this sector of the police was a well established part of the whole organisation as community policing priorities had existed long before central government policies of Neighbourhood Policing during the late 1990s. The department was involved in regular community policing activities which encompassed a range of tasks and functions which were not strictly 'soft' and servicebased, although were certainly framed around supporting and working with local citizens to address priorities. In Shore Acres most of the same infrastructure existed, but with a higher turnover of staff in the area compared with Hobart, which made setting up these types of initiatives more difficult. Comparable types of professional at similar rank level were in operation in Shore Acres, with most types of service also available; the exception was some drug support services and housing programmes which were more available in Hobart due to being in a different jurisdiction.

The specific multi-agency initiative which this paper principally addresses was framed around pooling resources, sharing information, and deploying staff to help support individual 
clients, most of whom were either showing signs of potential offending, or otherwise involved in relatively low-level forms of offending. A monthly case conference meeting was attended by a wide range of local agencies including the police, youth offending team, probation, housing landlords, education welfare, social work teams, drugs support services, mental health services, and drop-in centres/hostels or voluntary agencies involved in supporting clients. The case conferences were used to devise a planned set of actions to help support and steer the client away from engaging in various social problems ${ }^{6}$. The sorts of interventions created included referrals to counselling, or drug and alcohol support services, as well as informal and formal contractual injunctions including Acceptable Behaviour Contracts (ABCs) and Anti-Social Behaviour Order (ASBOs) (see McCarthy, 2010 for a description of these interventions). In addition to specific interventions, more informal resolutions were commonplace, such as highlighting concerns about an individual with a view to monitoring their status.

In policing literature, 'soft' policing activities have been associated with cynicism and critique within the broad masculine ethos which exists throughout the police organisation (Martin, 1999, Miller, 1999, Herbert, 2001). The fact that female officers dominate in these roles, both at management and operational levels, suggests that their presence in these roles could be due to their broader peripheral status within the police institution, in addition to inherent beliefs regarding women's caring and nurturing roles which the police frequently engender ${ }^{7}$. There were no formal regulations or legal requirements for the police to create such an initiative other than what they depicted as a pragmatic idea which also happened to provide a benevolent logic regarding the allocation of support mainly for young people and families on the fringes of criminality. Throughout the course of observing the case conference meeting it was apparent that female officers seemed to be the ones controlling and managing proceedings. The style and flow of the meetings was also conducted in a form which promoted regular dialogue and detail which extended beyond rationalistic, instrumental decision-making environments. As the following extract from a case conference describes, the types of language and framing were frequently linked to discussions extending far beyond issues of crime control and policing:

This was a new referral made by the police. Kate [Police Sgt] described the case (reading from the nomination form in front of her) as follows; 'She is 14 years old. Nominated because behaviour in home has got so bad that it can no longer be managed by her parents'.

Sian [Police Community Support Officer] continued following the slight pause 'She is known to misuse alcohol. Violent at home. She has assaulted her Mum on several occasions. Her older brother has to physically restrain her. Persistent truant. At this point Sian spoke about her work with Carla [young woman].

Sian: 'She is fed up of people asking 'what do you want? She doesn't trust anyone. Her counsellors apparently tell her Mum all the details of their sessions'. I will carry on seeing her twice a week. The CAHMS [mental health] referral needs to be sooner rather than later.' [Fieldnotes from Case Conference - Hobart]

Officers like Sian were deployed in their capacity as Police Community Support Officers (PCSOs) to operate as surrogate youth workers - engaged in building trust with local young people, working in local diversionary projects, liaising closely with schools, as well as possessing a juridical edge in evidence gathering and enforcement actions where necessary. This subtle blend of support and paternalism which has been described elsewhere in historical studies of female police officers (e.g. Jackson, 2003, 2005), illustrates the tutelary roles which female officers have often possessed in accordance with their vested operations in social 
service type cases. These types of police work were also heavily conditioned by a therapeutic mentality in terms of supporting and diverting young people away from various social problems, with crime just one feature of this type of case. This role in focusing on a wider range of social problems was facilitated by the police working closely with other community agencies - a feature which led to officers involved in multi-agency working having to reconcile their occupational identities in the wake of their collaborative working practices.

\section{Watering Down the Culture? Multi-Agency Working and Police Engagement}

The challenges which engaging in multi-agency environments can pose for the police have been well discussed elsewhere, with the most consistent theme of these studies suggesting that the police tend to dominate other agencies in quasi-authoritarian ways (Sampson et al, 1988, Crawford, 1997, Skinns, 2008). This has pointed to the dangers of alienating agencies with fewer material resources, or with agendas which conflict with those of the police. In addition, the literature on police cultures has described the authoritarian nature of the police organisation as having struggled historically to relinquish its powers and traditions of operating with 'outsiders', especially partner agencies. Manning's (1977) description of the police as a 'sacred canopy' which preserves its identity through its closely knit culture of values, beliefs, and ways of thinking has often been attributed to explaining the 'failures' of police reform projects. Examples include the difficulties in implementing community policing reforms (Herbert, 2005, Innes, 2005, Mastrofski et al, 2007), as well as struggles in accepting child protection and domestic abuse into mainstream police services (Hoyle, 1998, Garrett, 2004). In short, the orientation towards the police collaborating with agencies which come across as 'strange bedfellows' raises important questions not only about the role of gender in forging these relationships, but also about the impact which such relations have on the broader culture of the police.

Not only do the police tend to have greater resources available than many other agencies, in terms of the culture of the organisation, they tend to work in task-orientated, straight factual, direct ways. This can create tensions with the styles of engagement with agencies whose value base and modes of engagement with young people and families can be more persuasive, supportive, and without the ease by which to invoke legal powers to enforce clients to comply with their authority. In addition, the style of multi-agency working creates challenges regarding accountability and ownership of problems. In Shore Acres, which had a much more recent framework of multi-agency working, this initially caused a number of problems for the police to reconcile, with many comments from police officers at the beginning of the fieldwork explaining the source of discontent about the alleged inactions of other agencies:

My feeling is that there are agencies who are reluctant to give all information across and also find that some agencies work in a different way. The Police seem to be very task orientated, you ask us to do something we will go and do it. Other agencies don't work in quite the same way. They work with processes and if it doesn't fit the process it doesn't get done, or on time. I find that very difficult to deal with and frustrating. [Interview with Erica, police officer - Shore Acres].

Multi-agency working poses challenges for the police to engage in compromise with other agencies, work in collaborations outside the confines of meetings, and to share regular information with agencies. These activities raise questions about whether these working relations can affect both the organisational and occupational cultures of the police. Kate, the 
officer in charge of coordinating the ASB unit described her role in engineering multi-agency relations:

That multi-agency approach is just so important. But it takes a lot of hard work because you have to make sure that everyone's happy. It's like being a hostess at a big party - that's how I see it. It's about managing expectations. [Interview with Kate Police ASB lead caseworker - Hobart]

The police were the key agency in multi-agency working, both in terms of overall officers attending case conference meetings and the level of data and information which they would exchange with other agencies, as well as the fact that the administration and resource allocations were directly structured by the police. Hobart, which had a much more established multi-agency framework than Shore Acres, had also won the support of other agencies who viewed the role of the police as complementing and supporting their roles and functions, with few concerns about replication of tasks and 'treading on the toes' of their invested remits:

In an ideal world we could have every neighbourhood police officer trained up in counselling and child psychology and youth work skills and child development and things. But we don't live in an ideal world. I don't have any evidence of them sticking their boots in and making a mess of things, and creating bad relationships with young people. I don't have any evidence that is happening because they are human beings and have a human response and genuinely want to help. They don't want to be hard enforcers and do it with a smiley face, but genuinely want to address the wider needs of the young person. [Interview with Ewan, Children's Services Manager - Hobart]

The sentiments expressed in the quote above were shared by a number of agencies in Hobart where the police had spent a long period of time cultivating links and communicating these effectively with other agencies. In Shore Acres, where police engagement in preventive early intervention activities was comparably recent, there still existed some scepticism from other agency professionals, namely those from youth services and social work teams:

There is a talk social services and the mental health teams would like to have with their gatherers, their attractors $\{$ sic $\}$. I can see us going that way. The 'on the street team' for social services and mental health services. For all the ways we want to go that's one I would prefer because I can see it being vaguely more useful. I don't want to be the non-uniformed form of something else, fascist [laughs]. I don't like brown, it's not my colour ${ }^{8}$ [Interview with Rosa, Youth Worker - Shore Acres].

The increasing role of the police in preventive early intervention work actually led to a strengthening of the police's role as supporter and manager of the multi-agency group, especially in Hobart where their role had filled a clear void in the activities of Children's Services due to resource cutbacks and other organisational changes (Puffett, 2011). The police were however tactful and strategic in the ways they appropriated more social service based agendas whilst maintaining the involvement of other agencies. The suspicion of the police as megalomaniacs regarding multi-agency working featured as a surround attitude for some social service professionals, who although for the most part sharing similar views to Ewan in the account above, voiced concerns that the police's involvement in 'soft' policing had an ulterior motive in promoting hard edge tactics against vulnerable persons. 
As well as presenting challenges for the police to manage multi-agency relations, the management of intra-agency relations was a key area which had taken a number of years to cultivate:

Author: What was it like trying to build all the support and preventive work into the police when you first started?

KG: [pause] It was quite hard, it was about relationship building. But I am cheeky enough to say 'try it, if it doesn't work...' Quite interestingly it was like 'oh actually, I didn't know that was going to work'. So maybe there was a bit of luck when we started off, we had some good wins....it's about selling, about being a sales person and having a product that is good behind you. It's like if you are selling a car. You could be as confident as anything but if that car is absolutely pants [slang for low quality] people may try it but they'll bring it back. Whereas if you sell that car and its fantastic then people will keep coming back for it. It's about having things that work so they can rely on. The first time you try it, if it doesn't work then you can guarantee that they won't try it again. We are all busy people. But if you make sure its workable people talk. That has changed. Neighbourhood Teams are fine because they kind of get it, but we now get T\&P [Task and Patrol] officers who come up, even the vulnerable person's teams and the CID [Crime Investigation Department] are seeing that this team can actually enhance or complement what they are trying to do. [Interview with Kate - Police ASB Case Manager - Hobart].

As Kate's account demonstrates, there are several key attributes of police culture which can present initial barriers to the adoption of alternative policing strategies like multi-agency preventive/early intervention strategies. Amongst other female officers involved in this initial process of gaining acceptance for these modes of policing, there was a twin difficulty in gaining credibility and respect as a consequence of being female, as well as serving to promote a strategy of policing which could be easily labelled as 'soft' and thus potentially at odds with a dominant masculine value system shared by many officers. The pragmatic approach successfully delivered by Kate was perhaps an anomaly when compared with the numerous accounts which have been attributed to attempts to give organisational acceptance to such a model of policing as largely ignored or subjugated (Brown and Heidensohn, 2000, Westmarland, 2001). Not only had Kate been given the backing of senior officers, and funding to promote these strategies, she also had been allowed to enact a system for all new officers/probationers to spend time with the team including attending case conference meetings. This was sold by Kate and other 'pioneers' as a pragmatic tool - something which worked to solve cases before they reached an unmanageable level requiring vast resources and expenditure - and having a number of success stories to use as examples ${ }^{9}$.

\section{Legitimating 'Soft' Policing: Re-Framing Police Pragmatism and Duty}

The police's commitment to multi-agency working is structured internally through a need to preserve existing features of their occupational values. Unlike agencies such as social services whose ideological foundations exist in terms of a subtle blend of benevolent ideals and paternalistic responses, the police organisation is largely about preserving order and using the law as a mechanism through which to support these actions. This is not to suggest that the police cannot be supportive and orientate their service roles to help people, even those actively involved in low-level offending, but to point out that ideologically the police consistently find ways to reconcile accusations of being too soft ${ }^{10}$. The avoidance of the "pink 
and fluffy' label happened through the packaging of these responses as pragmatic tools commonsense ways of 'doing a job' as opposed to sowing the seeds for a clear cultural shift in ways of doing police work on a more dominant level.

Pragmatism is often associated with a kind of 'conceptual conservatism' (Crank, 1997). As Reiner writes 'police officers are concerned with getting from here to tomorrow (or the next hour) safely and with the least fuss and paperwork, which has made them reluctant to contemplate innovation, experimentation, or research' (Reiner: 2000:101). Pragmatism is often attributed to a 'hands on' mode of experience which treats ideologies, principles, and theories of policing with scepticism:

I think the Police culture is very pragmatic. I need to see that it works, they deal in facts. The majority of Police Officers have that attitude. There are one or two who can deal with concepts, but most police officers deal with facts. 'Well I am not going to accept partnership working is good until I have seen for myself.' [Interview with Brian, Community Safety Manager - Shore Acres]

In order for 'soft' policing programmes such as preventive youth work or early intervention to be accepted within the police organisation, officers conceive these as being pragmatic features which 'make sense' in terms of producing efficient and productive outcomes. By contrast, this is not predicated on a belief in the underlying principles of helping and supporting those 'at risk' of crime as benefits in their own right. For officers, the framing of the use of preventive early intervention initiatives accords with both a sense of duty, as well as with an awareness of practical realism:

What we would do is basically get our heads together and say from a police point of view we can work on this area, from a housing point of view we can work on this area, for education they can work on their bit. Basically it's so that you are trying to give that support to the family. It may be that they feel that they don't have any support, so it may be that social services need to get involved if they can do. And to try and give them all the opportunities and the support that we can to try and change the behaviours so that it doesn't affect the residents. [Interview with Lyn, Police Officer - Shore Acres]

Amongst female officers, in addition to the pragmatic features of adopting early intervention and similar preventive strategies, there was a specific focus on certain gendered qualities which gained much attention. These involved female officers casting an ambivalent response to overall issues of youth offending, commonly holding a level of expressed sympathy for the young person due to what were described as inadequate parents who failed in their duties to help their children:

Sean, an 11 year old boy had been referred on grounds of truanting from school and shoplifting. Concerns were raised about his mum, described as 'spending most of the day drunk'. Nicola [Police Officer] was further condemning of the mum's failure to parent her son, describing how Sean had just had surgery on his arm which had gone septic because she would not take him to hospital regularly to be cleaned. Sally [YOT Officer] was concerned by this, saying 'this is outright neglect'. The mood in the meeting was incredibly quiet, with sighs of disbelief expressed all round [Case Conference Discussion - Shore Acres] 
Female officers casting judgements about the 'respectability' of mothers were especially common, particularly where it was felt that the mother had 'failed' in her duties to both act responsibly as a women and as a supervisor of her children. This reflected similar 'othering' practices used by middle class persons in establishing identities through distinctions of not being working class (Skeggs, 1997, Lawler, 2005), especially mothers who failed to display the sufficient worth and independence in doing their best to help themselves and their children (see Dodson, 2007). In policing activities, these forms of class 'othering' practices can be often intertwined with one of the core aspects of police culture - that of mission. Here police work is viewed than more than a job - a vocation involving a purpose and a strong series of principles - what Reiner (2000:89) likens to 'the protection of the weak over the predatory'. In reality 'the predatory' is perhaps an ill-fitting word to describe most of the clients that the police encounter. Indeed, police officers frequently activate a moral vision regarding their duty to protect and 'go beyond the call of duty' to serve certain persons (e.g. Maynard Moody and Musheno, 2003).

Whilst 'child saving' policing activities remain traditionally situated as maternal tasks within the guise of 'soft' policing, these activities are carried out by both male and female officers on a frequent basis. Activities included carrying out home visits to the family, conducting one-to-one work with children and young people, referring them to support services, through to more advanced cases of seeking to help facilitate the removal of children from violent or 'neglectful' households. In such cases, there was a clear gendering of roles. In similar ways to Miller's (1999) research, male officers were more likely to view these tasks as important methods of crime control, although still showing humanity and sympathy for certain 'clients'. By contrast, female officers invoked a stronger referent to the moral duties and 'rescue' of 'redeemable' children as righteous acts in themselves, beyond any direct crime control impact - a response especially marked amongst female officers who also were parents (see Miller, 1999: 131-2). In this sense, 'soft' policing is not so much feminised directly in terms of the actual practice, but rather through the moralities of duty which were framed differently for male and female officers. These examples of 'child saving' have been explored elsewhere in studies of policing (esp Jackson, 2003, 2005), but have been less commonly linked to aspects of police culture, and how these gendered operations can draw together aspects of working missions, occupational moralities and humanitarian sides. Whilst these can be sidelined compared with the tough, macho attributes of police cultures associated with banishment and crime fighting styles of police work, these forms of 'respectability' distinctions by the same token activated forms of pathology towards mostly working class families, yet within the guise of 'rescue' and 'duty' which allowed these responses to be given a more acceptable purpose within policing cultures.

\section{Fluidities and Fragilities of Culture in Operation}

One of the dominant views expressed in studies of police occupational culture is the masculinised status of policing and the ways this can filter into policing practices (Fielding, 1994, Herbert, 1997, Reiner, 2000). Whilst this clearly continues to exist as a crucial component of the police's occupational status in accordance with their order maintenance remit, recent police reforms, including changes in the composition of police staff in England and Wales, pose a set of questions regarding the accuracy of this dominant narrative of police occupational culture. These revisions must also include acknowledgement of the social components of normative cultures of policing as not directly discriminatory against women in zero-sum forms, i.e. male officers dominating female officers through gender stereotyping and other forms of 'cop banter'. This is to suggest that gender and policing is more complex 
than simply the case of masculine values dominating and suppressing female officers who may wish to perform more nurturing type duties akin to ethics of care value systems. The police remain an agency with historical and legally defined roles which render them intrinsically masculine - that is, aside from the higher ratio of male to female officers, are the values incorporated within the occupational culture of the police as an organisation (Smith and Gray, 1985). As Fielding argues:

'The argument that policing is imbued with the values of masculinity is not perfect but is eased by the fact that readers would find utterly improbable the argument that policing is imbued within the values of femininity' (Fielding, 1994:63).

With respect to the changing structures of 'soft' policing activities under community policing reform, there is evidence that there have been some very real effects which invite policing scholars to re-examine the evidence for a specific police occupational culture. Miller's (1999:7) claim that 'the feminine attributes of caring associated with community policing will be redefined in order to be accepted into the existing masculinist "skill" framework' appears to have some merits. As this paper has explained, whilst the development of 'soft' policing activities may induce some changes to the working frames and modes of operation amongst police officers, the practice of these activities is often undertaken with a high degree of pragmatism and, at times, a sense of mission, which can have positive and negative consequences (McCarthy, 2010). 'Soft' policing activities have certainly become more accepted within the police organisation in the wake of community policing reforms, and have been more palatable through these key components of occupational police cultures. As Paoline writes:

'...in departments where the community policing message is clear and valued as an organisational philosophy, officers should feel less of a need to maintain the edge, become suspicious, and be isolated from their "partners" (citizens) of policing' (Paoline, 2003:208).

Paoline's work on police culture has called for a revised understanding of police culture based on the notion that the police organisation has become more complex via its growing remit of departments which seek to balance and deliver an increasing number of services and order maintenance functions. A key critique which Paoline launches is directed at studies which conceive of a singular dominant culture of the police organisation. One outcome of this issue is to portray a dominant culture operating at the expense of other cultures of policing which become suppressed or marginalised. In this, gender becomes part of the periphery as an important site of resistance and re-formulation of policing functions. In accordance with the aims of 'soft' policing which have been readily attributed to female officers, one should raise caution over confirming a convenient dichotomy between masculinity associated with men and femininity associated with women. As an essentialist position which has been well challenged in gender politics and queer theory (Butler, 1990, Sedgwick, 1990), there is a need to direct attention to the divergent ways and fluidities by which culture operates, including how dominant components of police culture may be appropriated and deployed (whether in intended or unintended ways) to create alternative modes of policing. It is through these micro sites that a more comprehensive understanding of police cultures can be achieved - a methodological critique as much as a theoretical one in embracing the particulars as well as the general occurrence of social patterns within policing cultures.

In the coming years the police, along with a range of other public services, will no doubt be forced into further cut-backs or revisions of existing resource allocations. 
Possibilities include the rolling back of 'soft' policing activities, with anti-terror and similar policing priorities protected (Travis, 2010). Alternatively, it may well be that the kinds of examples of policing activities described in this paper in fact become more frequent as the police organisation takes on board adaptive strategies to maintain its major public functions, whilst maintaining legitimacy and contact with a citizenry who will be unlikely to reserve judgement on the police's abilities to support these activities. For front-line female officers engaged in 'soft' policing functions, the current and future cultural reconfigurations of the police with multi-agency working could well become a more dominant part of the police's service delivery (Home Office, 2011).

\section{Conclusion}

Contrary to previous studies which have illustrated a general scepticism to the genuine adoption of 'soft' policing practices (e.g. Herbert, 2005, Mastrofski et al, 2007), this paper serves in some way as a success story, but with some notable caveats. Within the police culture literature the role of female officers is commonly associated with their marginalisation to 'soft' policing activities or duties which separate them from macho aspects of crime fighting. The police are not agents resistant to 'soft-style' policies per se, but rather careful in the ways they package and channel this type of response into acceptable cultural mentalities. The conveyance through pragmatic and mission orientations of police culture are key ways this can take place, arguing that it is not that 'soft' policing is necessarily viewed in negative ways within the police organisation, but rather that it creates a fundamental tension with its cultural acceptability as a symbolic attribute of conventional police work. This supports research conducted by Miller (1999) in the U.S.A which found that whilst male and female officers conducted 'soft' policing, it was the females who would acknowledge and show more genuine support for delivering these functions. In turn, female officers do not 'vie with and yield to particular, engendered stereotypes and associated roles' (Holdaway and Parker, 1998: 59), but operate in ways which serve to both reinforce and challenge dominant masculine conventions which structure police cultures.

Whilst there may be evidence to suggest that as a general trend the police continue to be a masculine, action-orientated, and largely macho organisation, more recent changes to the police organisation place limits on this hegemonic account. In accounting for the marginalisation of women through such accounts, there is an inherent danger of focusing too heavily on the overall outcomes of policing, rather than discovering some of the nuances in what can be considered as 'alternative' policing strategies as this paper describes, where the role of female officers is highly active, largely dominant, and at times subversive in its operation. This should not lead to a treatment of female officers through a utopic lens which articulates their behaviour as confirmation of a feminist model of direct resistance against their suppression and marginalisation by the police. Rather, the selling of 'soft' policing serves as an interesting example of a counter resistance which reconfigures existing components of police culture to produce support for a model of policing which attempts to be largely progressive in its aims and objectives.

\section{Notes}

\footnotetext{
${ }^{1}$ Whilst youth social crime prevention is the mainstay of this paper, it should also be recognised that female officers make up a significant proportion of other 'service' elements of the police organisation, including
} 
domestic violence, child protection and hate crime and victimisation (including victimisation on grounds of sexuality).

${ }^{2}$ Chan (2004) has also argued that police culture has degrees of dynamism, with fitting into the culture not a destined form for officers. Transcending this involves officers understanding the culture in reflexive ways, toward becoming 'creative individualists' (p.347).

${ }^{3}$ PCSOs are uniformed police officers established in England and Wales in 2002 to provide a reassuring presence and deal with low-level incivilities. Unlike formal police officers, they do not have powers of arrest, but have powers to issue fines and fixed penalty notices.

${ }^{4}$ Although this article does not focus on sexual orientation, there is evidence to suggest that the use of phrases such as 'airy fairy' reflect homophobic connotations, used primarily by male officers to establish heterosexual norms (see Herbert, 2001 for discussion). Myers et al (2004) have also argued that GLBT officers suppress their sexual orientation, and overemphasise the pragmatic components of police work as their core identities.

${ }^{5}$ This started initially with a male and female Sergeant present, although the male officer was redeployed in Hobart after six months.

${ }^{6}$ These include drug and alcohol issues, domestic abuse, mental health issues, truancy, running away from home, health problems, difficulties maintaining housing tenancies, to name just a few examples.

${ }^{7}$ For example, high ratios of women in child protection, domestic abuse, missing persons' roles suggest how the skill set is defined intrinsically by gender.

${ }^{8}$ Rosa's linkage between the police as brown shirt fascists was formed of numerous occasions where her work had been damaged by actions of police officers, including setting up a curfew in an area covering the youth centre. This animosity between Rosa and the police was ongoing throughout the course of the fieldwork.

${ }^{9}$ These successes included cases where joined-up information sharing had led to a decline in local problems of anti-social behaviour both at an individual and community level. Although not exclusively, these successes were associated with preventive responses, with some examples of enforcement action used in conjunction with these such as parenting orders or tenancy sanctions used by housing landlords.

${ }^{10}$ This is not to suggest that accusations of being 'too hard' can also figure, although for the content of this paper this theme will not be approached.

\section{References}

Becker, H (1998) Tricks of the Trade, Chicago, University of Chicago Press

Boyatzis, R (1998) Transforming Qualitative Information: Thematic Analysis and Code Development, London, Sage

Brogden, M (1991) On the Mersey Beat: Liverpool between the Wars, Oxford, Oxford University Press

Brown, J (1998) 'Aspects of Discriminatory Treatment of Women Police Officers Serving in Forces in England and Wales', British Journal of Criminology, 38 (2), 265-282

Brown, J, Heidensohn, F (2000) Gender and Policing, London, Macmillan

Butler, J (1990) Gender Trouble: Feminism and the Subversion of Identity, London, Routledge

Chan, J (1997) Changing Police Cultures, Cambridge, Cambridge University Press

Chan, J (2004) 'Using Pierre Bourdieu's Framework for Understanding Police Culture', Droit et Société, 56-57, 327-347

Crank, J, P (1997) Understanding Police Culture, Cincinnati, Anderson Publishing 
Crawford, A (1997) The Local Governance of Crime: Appeals to Community and Partnerships, Oxford, Clarendon Press

Dodson, L (2007) 'Wage-Poor Mothers and the Moral Economy', Social Politics, Vol 14, 258-280

Fielding, N (1994) 'Cop Canteen Culture', in Newburn, T, Stanko, E (eds), Just Boys Doing Business: Men, Masculinity and Crime, London, Routledge

Fielding, N (2002) 'Theorising Community Policing', British Journal of Criminology, 42 (1), 147-163

Fielding, N (2005) Policing and Social Conflict, London, Glasshouse Press

Fielding, N, Fielding, J (1992) 'A Comparative Minority: Female Recruits to a British Constabulary Force', Policing and Society, 2 (3), 205-218

Flick, U (1998) An Introduction to Qualitative Research: Theory, Method, and Applications, London, Sage

Garrett, M (2004) 'Talking Child Protection: The Police and Social Workers 'Working' Together', Journal of Social Policy, 4 (1), 77-97

Heidensohn, F (1992) Women in Control? The Role of Women in Law Enforcement, Oxford, Clarendon Press

Herbert, S, K (1997) Policing Space: Territoriality and the Los Angeles Police Department, Minneapolis, Minnesota University Press

Herbert, S, K (1998) 'Police Subculture Reconsidered', Criminology, 36 (2), 343-370

Herbert, S, K (2001) 'Hard Charger' or 'Station Queen'? Policing and the Masculinist State', Gender, Place and Culture, 8 (1), 55-71

Herbert, S, K (2005) Citizens, Cops and Power, Chicago, University of Chicago Press

Holdaway, S (1983) Inside the British Police, London, Blackwell Publishing

Holdaway, S, Parker, S (1998) 'Policing Women Police: Uniform Patrol, Promotion and Representation in the CID', British Journal of Criminology, 38 (1), 40-60

Home Office (2004) Building Communities, Beating Crime, London, HMSO

Home Office (2010) Safe and Confident Neighbourhood Strategy, London, HMSO

Home Office (2011) Policing in the 21 $1^{\text {st }}$ Century: Reconnecting Police and the People, London, HMSO (consultation document)

Hoyle, C (1998) Negotiating Domestic Violence, Oxford, Clarendon Press 
Innes, M. (2005) 'Why 'soft' policing is hard: On the curious development of Reassurance Policing, how it became Neighbourhood Policing and what this signifies about the politics of police reform', Journal of Community and Applied Social Psychology, 15(3), 156-169

Jackson, L (2003) 'Care or Control? The Metropolitan Police and Child Welfare', The Historical Journal, 46 (3), 623-648

Jackson, L (2005) Women Police: Gender, Welfare and Surveillance in the Twentieth Century, Manchester, Manchester University Press

Lawler, S (2005) 'Disgusted Subjects: The Making of Middle-Class Identities', The Sociological Review, 53 (3), 429-46

Loftus, B (2009) 'Police Occupational Culture: Classic Themes, Altered Times', Policing and Society, 20 (1), 1-20

Manning, P, K (1977) Police Work: The Social Organisation of Policing, Cambridge: MA, MIT Press

Martin, S (1980) "Breaking and Entering": Policewomen on Patrol, Berkeley: CA, University of California Press

Martin, S (1999) 'Police Force or Police Service'? Gender and Emotional Labor', Annals of American Academy Political and Social Science, 561, 111-126

Mastrofski, S, Willis, J, Rinehart-Kochel, T (2007) 'The Challenges of Implementing Community Policing in the United States', Policing, 1 (2), 223-234

Maynard-Moody, S, Musheno, M (2003) Cops, Teachers and Councillors: Stories from the Front Lines of Public Service, Ann Arbor, University of Michigan Press

McCarthy, D, J (2010) 'Self-Governance or Professionalized Paternalism? The Police, Contractual Injunctions and the Differential Management of Deviant Populations', The British Journal of Criminology, 50 (5), 896-913

Miller, S (1999) Gender and Community Policing: Walking the Talk, Boston, Northeastern University Press

Myers, K, Forest, K, Miller, S (2004) 'Officer Friendly and the Tough Cop: Gays and Lesbians Navigate Homophobia and Policing', Journal of Homosexuality, 47 (1), 17-37

Patton M, Q (2002) Qualitative Research and Evaluation Methods (3rd ed.), Thousand Oakes: CA, Sage Publications

Paoline, E (2003) 'Taking Stock: Towards a Richer Analysis of Police Culture', Journal of Criminal Justice, 31, 199-214 
Puffett, N (2011) 'Children's services take hit of more than half a billion pounds', Children and Young People Now, 8/3/11

Rabe-Hemp, C (2009) 'POLICEwomen or policeWOMEN? Doing Gender and Police Work', Feminist Criminology, 4 (2), 114-129

Reiner, R (2000) The Politics of the Police ( ${ }^{\text {nd }}$ ed), Oxford, Oxford University Press

Sampson, A, Stubbs, P, Smith, D, Pearson, G, Blagg, H (1988) 'Crime, Localities and the Multi-Agency Approach, British Journal of Criminology, Vol 28, 478-93

Sedgwick, E, K (1990) Epistemology of the Closet, Berkeley and Los Angeles, University of California Press

Skeggs, B (1997) Formations of Class and Gender: On Becoming Respectable, London, Sage

Skinns, L (2008) 'A Prominent Partner? The Role of the State in Police Partnerships', Policing and Society, 18 (3), 311-321

Smith, D, J, Gray, J (1983) The Police in Action. Police and People in London: vol. 4. London, Policy Studies Institute.

Travis, A (2010) 'Police Forces Facing 'Deep Cuts' to Number of Front-Line Officers', The Guardian, 13/10/2010

Walby, S (1997) Gender Transformations, London, Routledge

Westmarland, L (2001) Gender and Policing: Sex, Power and Police Culture, Cullompton, Willan Publishing

\section{Acknowledgements}

A version of this paper was presented to the meeting of the Law and Society Association in San Francisco, June 2011. Thanks to audience members and to the discussant, Professor Catalina Smulovitz for helpful comments. I also acknowledge the supportive and helpful comments from the two anonymous reviewers. 